\title{
Founder's lecture of the ISS 2006: borderlands of normal and early pathological findings in MRI of the foot and ankle
}

\author{
Zanetti, M
}

\begin{abstract}
The purpose of this article is to highlight the anatomical variants, technical pitfalls, and the prevalence of abnormal conditions in the asymptomatic population in magnetic resonance imaging of the foot and ankle. Special attention is drawn to the complex anatomy of the deltoid ligament (the superficial tibionavicular ligament, tibiospring ligament, the tibiocalcaneal ligament, and the deep anterior and posterior tibiotalar ligaments) and the posterior tibial tendon insertion including the magic angle artifact and the high prevalence of asymptomatic findings such as "hypertrophied" peroneal tubercle (abnormal only when larger than $5 \mathrm{~mm}$ ), peroneus quartus (prevalence 17\%), and cysts (vascular remnants) just inferior to the angle of Gissane.
\end{abstract}

DOI: https://doi.org/10.1007/s00256-008-0515-7

Posted at the Zurich Open Repository and Archive, University of Zurich ZORA URL: https://doi.org/10.5167/uzh-13081

Journal Article

Published Version

Originally published at:

Zanetti, M (2008). Founder's lecture of the ISS 2006: borderlands of normal and early pathological findings in MRI of the foot and ankle. Skeletal Radiology, 37(10):875-884.

DOI: https://doi.org/10.1007/s00256-008-0515-7 


\title{
Founder's lecture of the ISS 2006: borderlands of normal and early pathological findings in MRI of the foot and ankle
}

\author{
Marco Zanetti
}

Received: 17 April 2008 / Accepted: 24 April 2008/Published online: 5 June 2008

(C) ISS 2008

\begin{abstract}
The purpose of this article is to highlight the anatomical variants, technical pitfalls, and the prevalence of abnormal conditions in the asymptomatic population in magnetic resonance imaging of the foot and ankle. Special attention is drawn to the complex anatomy of the deltoid ligament (the superficial tibionavicular ligament, tibiospring ligament, the tibiocalcaneal ligament, and the deep anterior and posterior tibiotalar ligaments) and the posterior tibial tendon insertion including the magic angle artifact and the high prevalence of asymptomatic findings such as "hypertrophied" peroneal tubercle (abnormal only when larger than $5 \mathrm{~mm}$ ), peroneus quartus (prevalence 17\%), and cysts (vascular remnants) just inferior to the angle of Gissane.
\end{abstract}

Keywords MRI, foot and ankle $\cdot$ Normal anatomy, foot and ankle $\cdot$ Variants and pitfalls, foot and ankle

\section{Introduction}

It is the radiologist's cornerstone to decide if imaging findings are normal or abnormal. Juergen Freyschmidt, Bremen, Germany, gold medalist recipient of the International Skeletal Society (ISS) in Vancouver 2006, has contributed substantially with his unique text book entitled "Borderlands

The ISS Founder's lecture honoring Professor Juergen Freyschmidt, Division of Diagnostic Radiology and Nuclear Medicine,

Zentralkrankenhaus, Bremen, Germany, has been delivered at the 33rd Members Meeting of the ISS held in Vancouver, September 2006.

This review article is based on the 2006 Founder's lecture.

M. Zanetti $(\bowtie)$

Radiology, University Hospital Balgrist,

Forchstr. 340,

8008 Zurich, Switzerland

e-mail: marco.zanetti@balgrist.ch of Normal and Early Pathological Findings in Skeletal Radiography" [1] for the differentiation between clinically significant and insignificant findings in musculoskeletal radiology. Analogous to his textbook, the Founder's lecture 2006 of the ISS was entitled "Borderlands of Normal and Early Pathological Findings in MRI of the Foot and Ankle" and covered anatomical variants, technical pitfalls, and prevalence of asymptomatic pathologic conditions in magnetic resonance (MR) imaging of the foot and ankle. This review article discusses such findings in ligaments, tendons, and bone marrow.

\section{Ligaments}

Supination (inversion) injury of the ankle is one of the most common injuries in the general population and athletes. Although the majority respond to rehabilitation, $15-20 \%$ of sports injuries can result in persisting symptoms, and MR imaging may be required for the evaluation of the collateral ligaments of the ankle [2].

Lateral collateral ligaments

The lateral collateral ligament complex consists of three major parts: the anterior talofibular (ATF), the calcaneofibular (CF) ligament, and the rarely torn posterior talofibular ligament.

\section{Anterior talofibular ligament}

The ATF ligament extends from the fibula tip perpendicular to the long axis of the fibula to the proximal-lateral aspect of the talar head. The ATF ligament is easily seen on transverse MR images. The normal ATF ligament is thin and has low-signal intensity on all sequences (Fig. 1a). A 
Fig. 1 a The normal ATF ligament (arrow) as a thin and lowsignal-intense structure is shown on a transverse $\mathrm{T} 2$-weighted MR image. b Transverse T2-weighted MR image from the same asymptomatic volunteer as shown a demonstrates that a diagnostic error may occur when the ligament is assessed 1 or $2 \mathrm{~cm}$ above the fibular tip. At this location, a physiological gap (arrow) is present
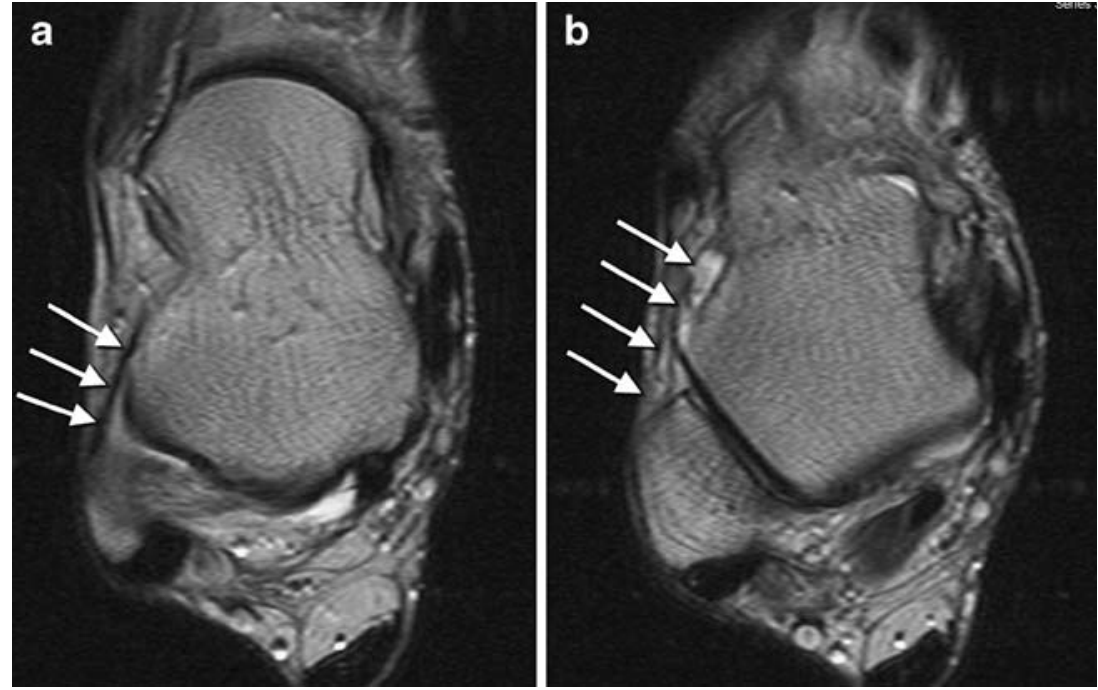

pitfall may occur when the ligament is assessed 1 or $2 \mathrm{~cm}$ above the fibular tip. At this location, a physiological gap is present (Fig. 1b).

\section{Calcaneofibular ligament}

The course of the CF ligament is variable. Based on a cadaveric study including 75 ankles, only 14 (19\%) CF ligaments were parallel to the long axis of the fibula [3]. Three (4\%) CF ligaments were perpendicular to the fibula, two (3\%) were fan-shaped, and 75\% (56 of 75) showed an oblique course with an angle between $10^{\circ}$ and $45^{\circ}$ against the fibula. Due to this oblique course of the CF ligament, on coronal and transverse images, the CF ligament needs to be analyzed on several adjacent images (Fig. 2). Therefore, additional oblique MR sequences have been suggested for evaluation [4]. Considering the large variation of the ligament course, we prefer to use secondary reconstructions. Three-dimensional (3D)-gradient echo 3D images have been suggested [5] for secondary reconstructions, but standard T2-weighted turbo spin-echo sequences provide similar secondary reconstructions of the CF ligament [6]. This technique allows quick analysis of the CF ligament on a single reconstructed MR image (Fig. 2).

\section{Tibiofibular syndesmosis}

The distal tibiofibular syndesmosis is a complex structure characterized by four separate ligaments: the anterior inferior tibiofibular ligament, the posterior inferior tibiofibular ligament, the transverse tibiofibular ligament, and the interosseous ligament. In chronic injuries, the injured ligament can show variable configurations while healing, and its signal alteration can return to normal and therefore render it indistinguishable from uninjured ligaments [7]. A tibiofibular syndesmosis tear is characterized by increased signal through the anterior tibiofibular syndesmosis. Contrastenhanced sequences increase the accuracy of tibiofibular syndesmosis tears [7, 8]. Although an abnormal upward extension (more than $1 \mathrm{~cm}$ ) of the syndesmotic recess has been described as an ancillary sign for tibiofibular syndesmosis tear, caution is required [9]. Physiological increased signal in the syndesmotic recess and a prominent vessel outside the anterior tibiofibular ligament may mimic a tibiofibular syndesmosis tear (Fig. 3).

\section{Medial collateral ligaments}

Injury to the medial collateral ligaments-also called deltoid ligaments - is much less common than lateral collateral ligament injuries, accounting for approximately $15 \%$ of ligament trauma. Insufficiency of the medial collateral ligaments may lead to ankle instability, posteromedial impingement, and osteoarthritis [10, 11].

The deltoid ligament is composed of superficial and deep layers. The superficial layer consists of (from anterior to posterior) the tibionavicular ligament, tibiospring ligament, and the tibiocalcaneal ligament. The anterior and posterior tibiotalar ligaments are from the deep layer. Ligament lesions are characterized by signal changes or absence of ligament visibility. The normal signal of the ligaments is low on T1- and T2-weighted MR images with one notable exception. The posterior tibiotalar ligament (Fig. 4) is striated, specifically in individuals younger than 45 years [12]. The absence of visibility (in 55\% [12]) of the anterior tibiotalar ligament (Fig. 5) on MR images of healthy volunteers is in accordance with a cadaveric study where the ligament was also only present in 50\% [13]. In contrast to the absence of visibility of the anterior tibiotalar ligament, the absence of visibility of the tibionavicular ligament in 

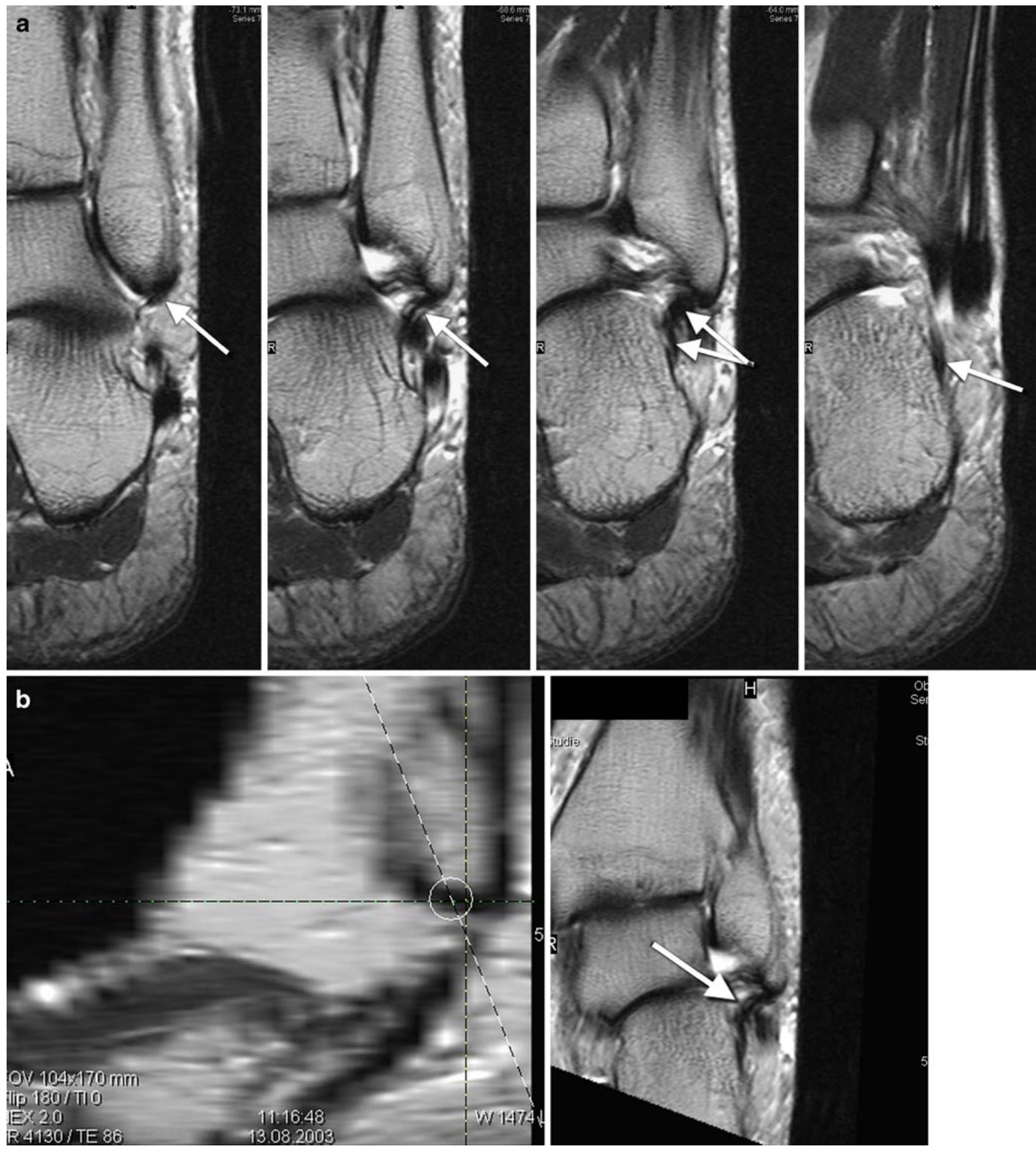

Fig. 2 a The normal CF ligament (arrows) in an asymptomatic volunteer demonstrates that the $\mathrm{CF}$ ligament needs to be analyzed on several adjacent images due to its oblique course. b Secondary

reconstruction of the CF ligament based on the same standard spinecho images as shown in a permits quick analysis of the CF ligament on a single image

$55 \%$ of asymptomatic volunteers cannot be explained by anatomical reasons. In cadavers, the tibionavicular ligament, notably an important stabilizer [10], is a consistently seen structure [14]. The lesser visibility of the tibionavicular ligament (Fig. 6) can be improved by oblique imaging planes-either with $40^{\circ}$ to $50^{\circ}$ plantar-flexed foot and transverse imaging [15] or with secondary reconstruction either with thin-gradient echo images [15] or with 3- to 


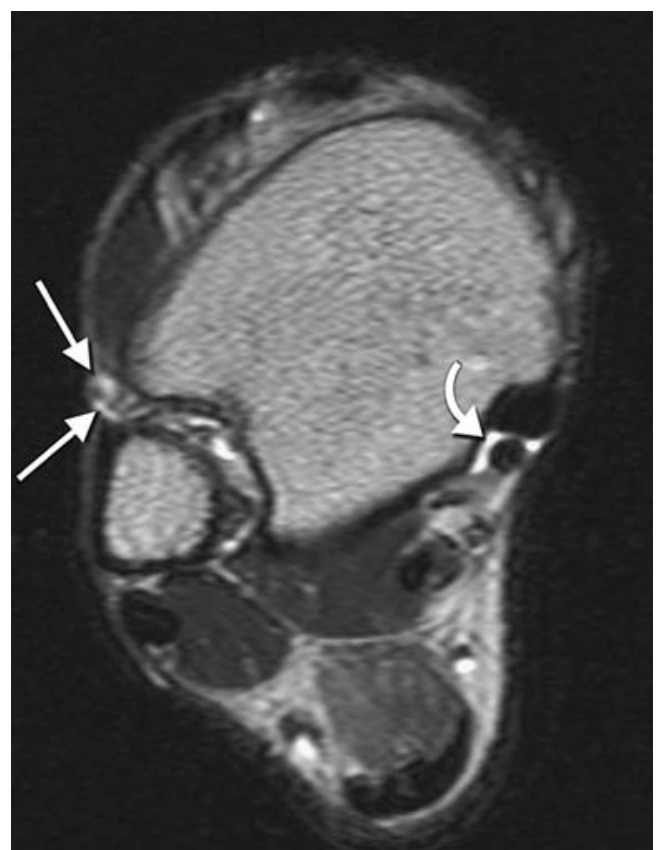

Fig. 3 Transverse T2-weighted image from an asymptomatic volunteer demonstrates that prominent vessels (straight arrows) outside the anterior tibiofibular ligament may mimic a tibiofibular syndesmosis tear. A physiologic amount of fluid is visible around the flexor digitorum tendon (curved arrow)

4-mm-thick conventional turbospin-echo sequences [6]. We prefer the use of secondary reconstructions based on standard spin-echo sequences (Fig. 6). Signal changes on standard spin-echo sequences are more characteristic than those on seen gradient echo MR images.

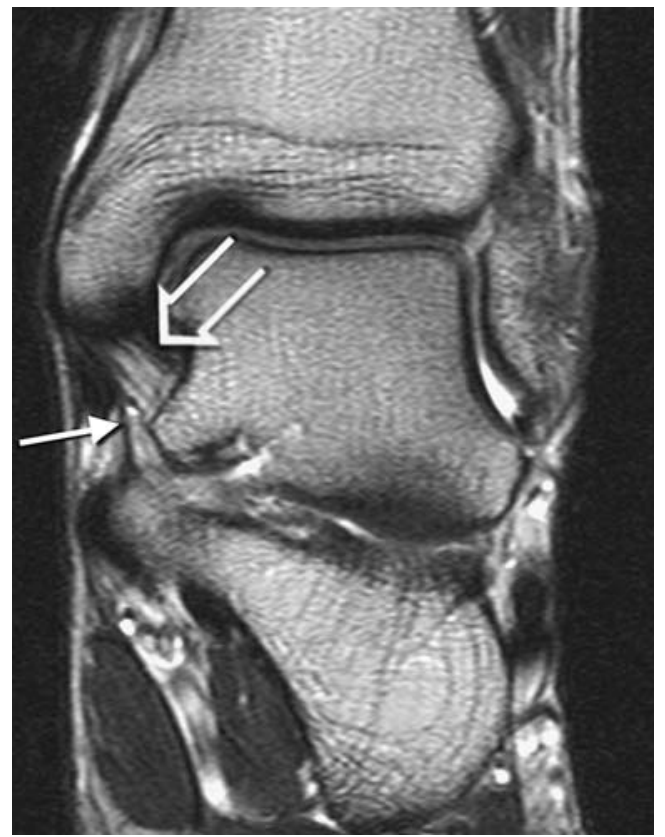

Fig. 4 The normal striated posterior tibiotalar ligament (open arrow) and the thin tibiocalcaneal ligament (thin arrow) are shown on a coronal T2-weighted MR image

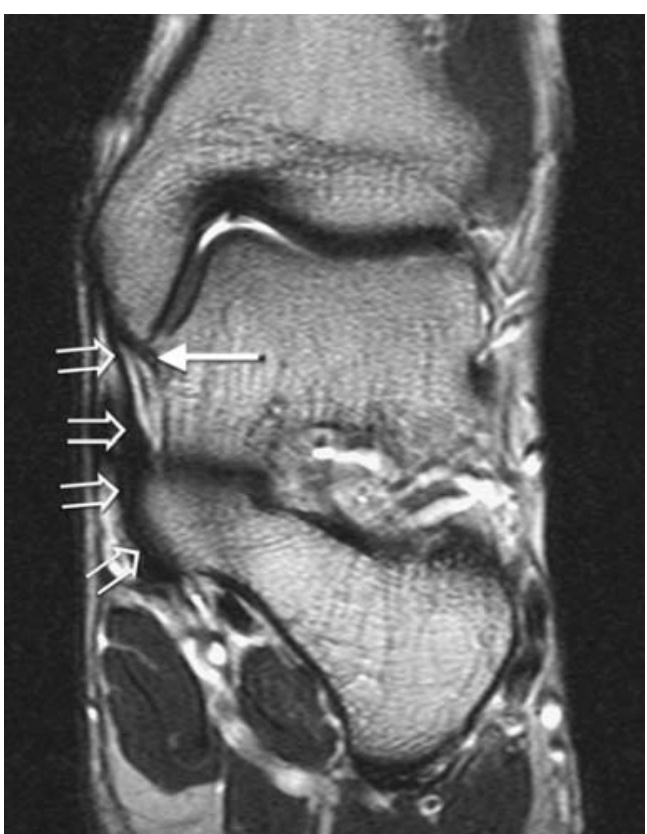

Fig. 5 The normal anterior tibiotalar ligament (thin arrow), which is present in only $50 \%$ of all individuals, is shown on a coronal T2weighted MR image. The normal tibiospring ligament is demonstrated by the open arrows

\section{Tendons}

\section{Posterior tibial tendon}

Posterior tibialis tendon dysfunction has been recognized as a disabling cause of progressive flatfoot deformity in middle-aged patients. The MR diagnosis of the partial tear of the posterior tibial tendon (PTT) is substantiated by caliber changes and contour changes of the tendon, increased signal within the tendon, and associated increased fluid in the tenosynovium. The tibial posterior tendon insertion is complex (Fig. 7). The largest most anterior component is in direct continuity with the main tendon and has a broad cone-shaped insertion on the navicular tuberosity and the medioinferior surface of the first cuneiform. The middle component continues inferolaterally into the sole of the foot and inserts at the second and third cuneiform, the cuboid, and the base of the second, third, forth, and, irregularly, the fifth metatarsals. The several components of the PTT insertion produce on transverse images contour irregularity and signal changes. The increased signals on T1-weighted images may be caused by interfering fatty tissue between the individual tendon insertions or by the presence of a fibrocartilage accessory navicular bone [16]. However, by far, the most common reason for increased signal on $\mathrm{T} 1$-weighted or proton density-weighted images at the insertion of the posterior tibial in asymptomatic persons (in 97\% [17]) is the magic angle artifact. The magic angle artifact can be substantially 

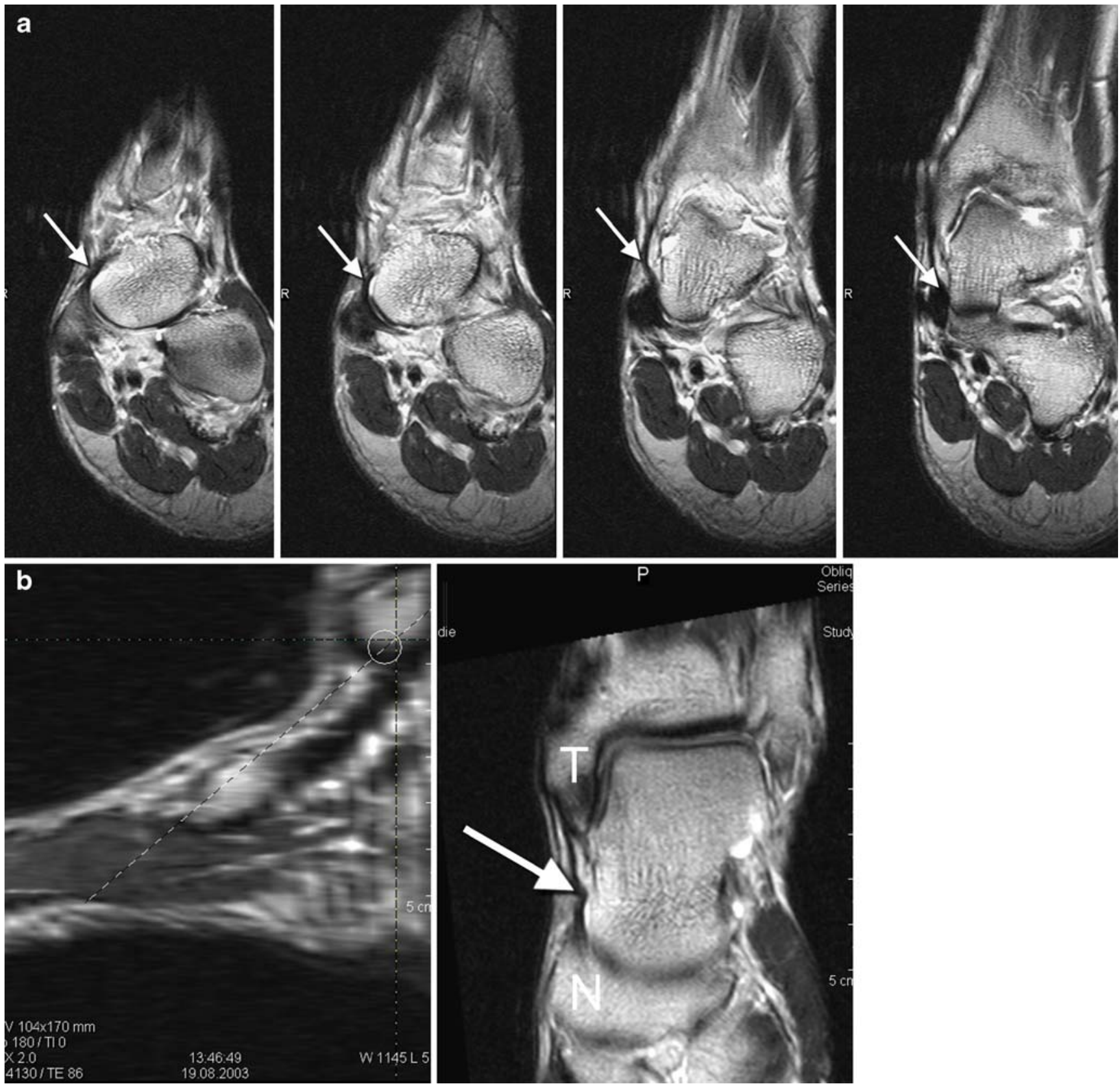

Fig. 6 a On coronal T2-weighted standard images, the tibionavicular ligament (arrows) has to be analyzed in several adjacent MR images. b The secondary reconstruction of the tibionavicular ligament from

the same coronal T2-weighted standard images shown in a allows the visualization of the entire ligament from the tibia to the navicular bone

reduced when patients are scanned in the prone position instead of the neutral supine position (Fig. 7b). Alternatively, the magic angle artifact can be reduced when patients are scanned in the supine position and with a strict plantar flexion of the foot. Finally, magic artifacts can be prevented when the echo time is increased more than $38 \mathrm{~m}$ but sensitivity for tendinopathy drops.

Increased amount of fluid within the tendon sheath should be substantial to be considered as abnormal. Small amounts of fluid within the tendons sheath have a high prevalence in asymptomatic feet (16-31\% [18]).

\section{Anterior tibial tendon}

Anterior tibial tendon (ATT) abnormalities are less common than PTT abnormalities. Nevertheless, hypoxic degenerative tendinosis or mucoid degeneration occurs and may lead to a partial or complete tear of the ATT. Characteristic MR findings of ATT abnormalities include tendon thickening $(>5 \mathrm{~mm})$ and signal intensity abnormalities of the tendon within $3 \mathrm{~cm}$ from the distal point of insertion [19]. In contrast to the PTT, signal changes at the ATT insertion are rarely caused by a magic artifact $(<20 \%$ [17]). Other 


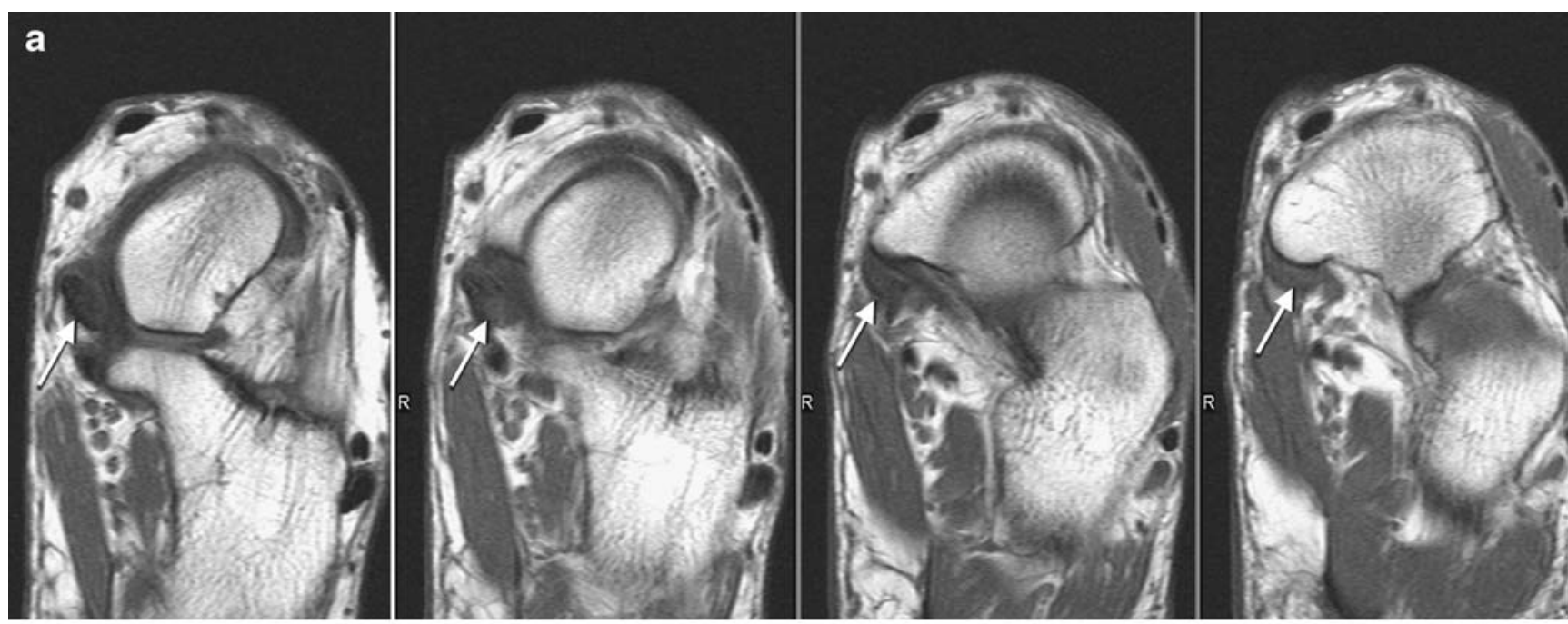

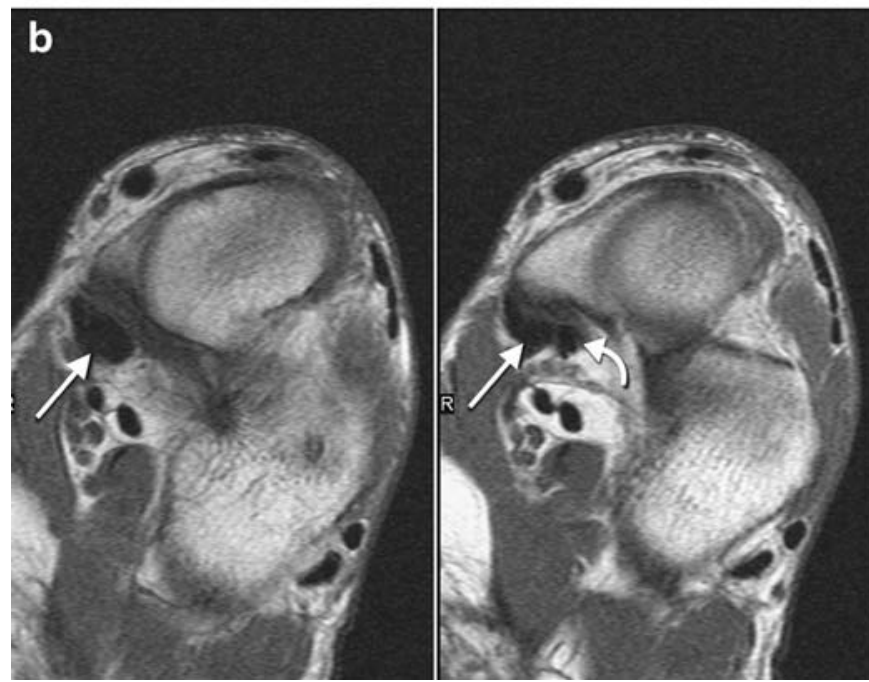

Fig. 7 a The complex insertion of the tibial posterior tendon (arrow) in an asymptomatic volunteer is shown. The several components of the posterior tibial tendon insertion produce on transverse images contour irregularity and signal changes. The thickening of the posterior tibial tendon at the insertion is normal. The increased signal in the posterior tibial tendon is caused by a magic angle artifact. Signal intensity is normalized when the patient is scanned in the prone position (see b). b The magic artifact is almost completely diminished

confusing findings are tendons splits. Although Khoury et al. [20] reported a case of longitudinal split of the ATT with surgical correlation, a longitudinal split of the distal portion of the ATT represents, rather, a normal variant. A longitudinal split of the distal part of the ATT is commonly visible in asymptomatic feet (18\% in Mengiardi et al. [19]; Fig. 8).

\section{Peroneal tendons}

Longitudinal split tears of the peroneus brevis tendon have been increasingly reported as a source of lateral ankle pain and disability. In contrast to the ATT, splits of the peroneus brevis tendon are considered as pathologic conditions and are not encountered in asymptomatic ankles. Anatomic and

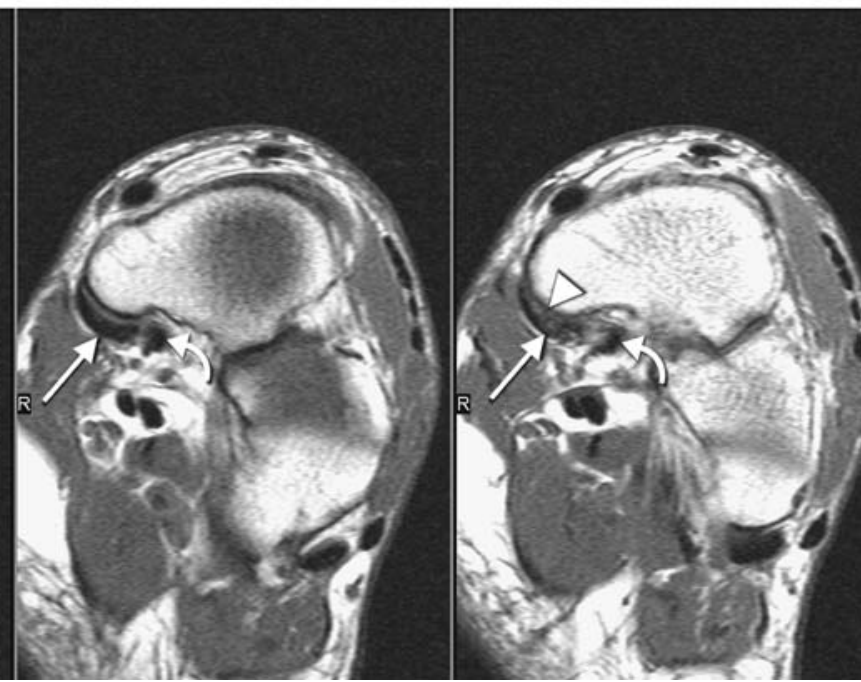

when the same volunteer as shown in a is scanned in the prone position instead of the neutral supine position. The subtle increase in signal at the inner side of the posterior tibial tendon is caused by the presence of a fibrocartilage accessory navicular bone (arrowhead). The remaining contour irregularity is caused by individually seen tendon bundles, e.g., the bundle (curved arrow) running to the base of the metatarsals

histologic reports have suggested that the split develops from prolonged mechanical attrition within the fibular groove [21]. Mechanical attrition have been associated with anatomic variants such as the flattened fibular groove, peroneus quartus, low-lying peroneal muscle belly, enlarged peroneal tubercle, and enlarged retrotrochlear eminence [22]. However, many of these anatomic variants are present on MR images in volunteers with asymptomatic ankles [23]. In a series of 65 asymptomatic ankles, 72\% ankles exhibited convex, flat, or irregular fibular grooves that are considered to predispose individuals to peroneal tendon dislocation and tendon irritation. In the same series of volunteers, peroneus quartus muscles were (Fig. 9) seen in $17 \%$. It seems that peroneus quartus rarely causes 
Fig. 8 A longitudinal split variant of the distal part of the ATT is shown a transverse oblique T1-weighted MR image in an asymptomatic foot

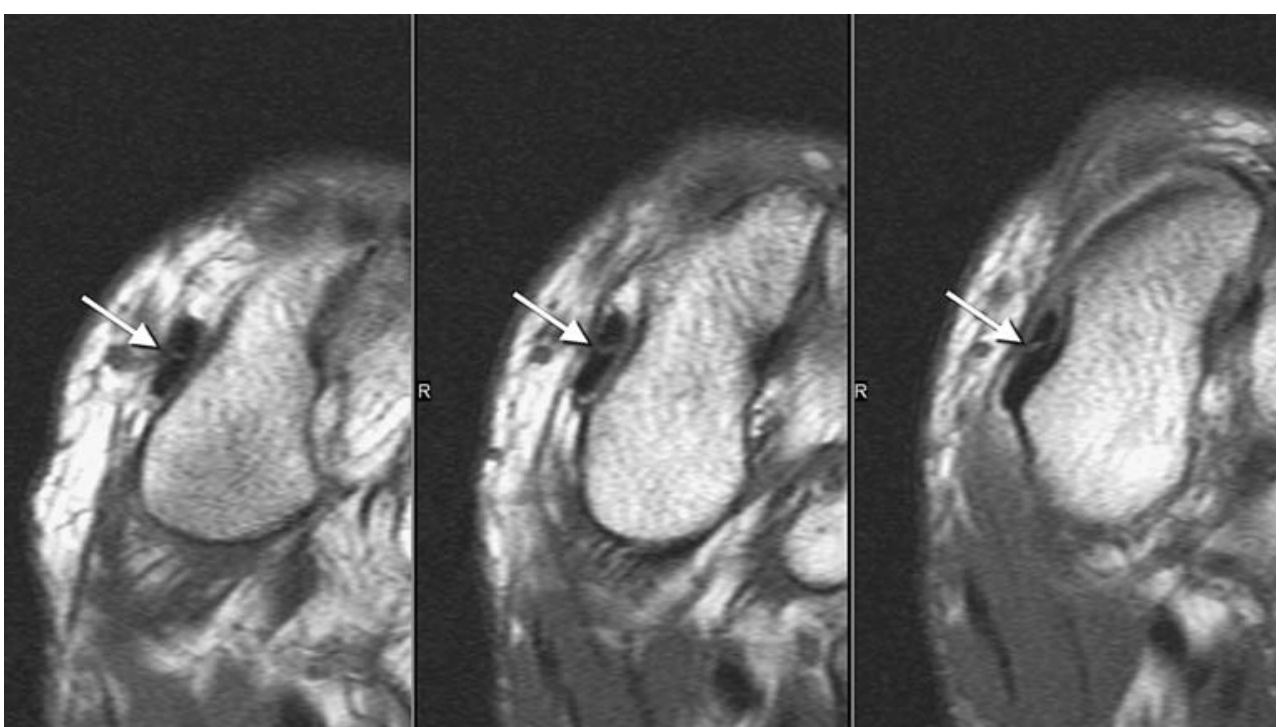

crowding in the retromalleolar fibular groove. Low-lying peroneal muscle bellies-another potential cause for crowding in the retromalleolar fibular groove-is defined as an extension of the muscle tissue distal to the fibular tip. However, again, the distal extension of the musculotendinous junction is highly variable. Ninety percent of the musculotendinous junctions of the peroneus brevis are located in a range between $27 \mathrm{~mm}$ proximal to $13 \mathrm{~mm}$ distal to the fibular tip. Thus, a low-lying peroneus brevis muscle belly should only be diagnosed in cases with muscle extension more than $15 \mathrm{~mm}$ distal to the fibular tip. Along the lateral aspect of the calcaneus, two osseous prominences are visible. At the anterolateral aspect of the calcaneus, the clinically more important peroneal tubercle is seen in approximately $60 \%$ of ankles. It splits the peroneus brevis tendon from the peroneus longus tendon. The mean height

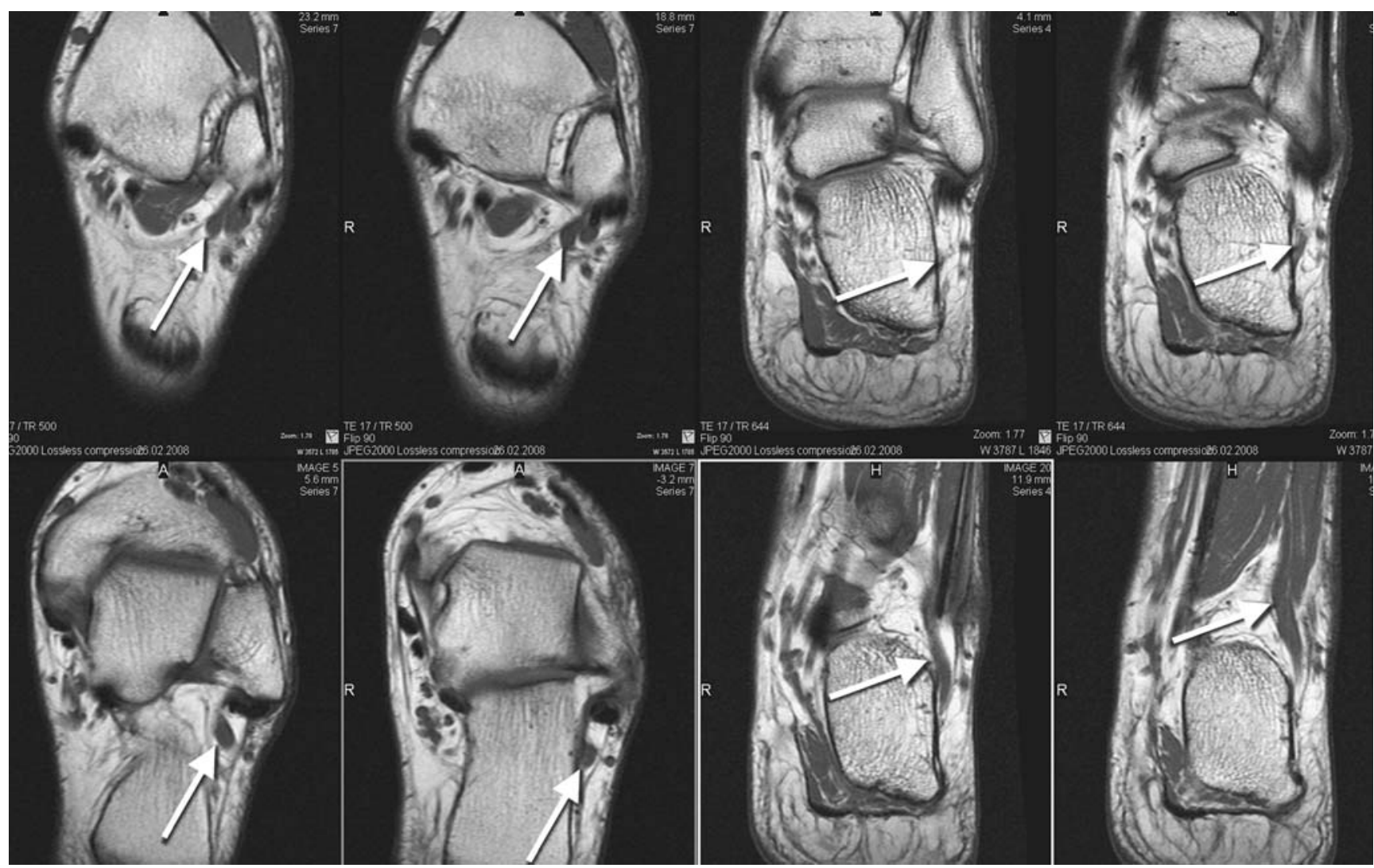

Fig. 9 Four consecutive transverse T1-weighted MR images (left side) and four consecutive coronal T1 weighted MR images (right side) show the course of the peroneus quartus (arrows) muscle in an asymptomatic volunteer 


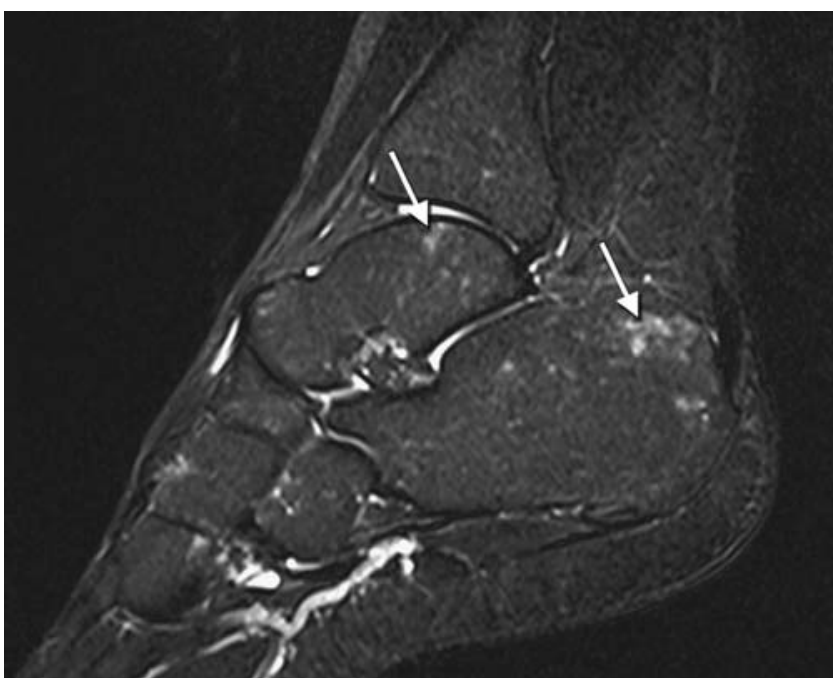

Fig. 10 Islands of red marrow (arrows) are revealed on a sagittal STIR sequence of an asymptomatic volunteer

is $3 \mathrm{~mm}$ but rarely exceeds $5 \mathrm{~mm}$ (cutoff $5 \mathrm{~mm}=90 \mathrm{th}$ percentile). A cutoff of $5 \mathrm{~mm}$ can also be used to diagnose an enlarged retrotrochlear - the second osseous prominence in the lateral aspect of the calcaneus.

Care should also be taken to distinguish between tendinosis and a magic angle artifact as in other foot and ankle tendons [17].

\section{Bone marrow}

MR abnormalities with increased signal on T2-weighted or short inversion time inversion recovery (STIR) images in the foot and ankle are found in a wide array of conditions including occult fractures, osteochondral defects, disorders of tendons with subtendinous bone marrow abnormalities, osteoarthritis, inflammatory arthropathies, osteomyelitis, neuropathic arthropathy, and benign and malignant neoplasms [24-33]. Such abnormalities are clinically relevant and are often associated with pain [26,34-36]. On the other hand, an increased signal on STIR images may also represent normal variants or clinically asymptomatic abnormalities [37]. Bone marrow changes on STIR MR images are commonly (50\% [37]) detected in asymptomatic feet and ankles. However, they are very small $(<1 \mathrm{~cm})$ or subtle and should not lead to further diagnostic workup or treatment without any additional abnormalities. In younger individuals up to the age of 25 years, isolated islands of red marrow may persist $[38,39]$. Islands of red marrow can be seen occasionally as multiple tiny spots (Fig. 10). In cases with extensive bone marrow changes, the contralateral foot can be examined for comparison.

In elderly individuals, edema-like bone marrow changes in the lower extremity may be attributed to mechanical stress reaction (initial phase of a stress fracture or insufficiency fracture). The pathogenic mechanism of initial insufficiency fracture may also explain that bone marrow edema-like changes are seen after foot immobilization when osteoporosis has occurred after rest. A bone marrow edema pattern appears most often within the first 12 weeks after completion of immobilization therapy and does not correlate well with new symptomatology or pain [40]. Eighteen weeks after the immobilization period resolution or stabilization of bone marrow signal, with no continued evolution, should be expected. Patients with bone marrow
Fig. 11 T2-weighted turbo spin-echo MR image (left side) and T1-weighted spin-echo images (right side) reveal bone marrow changes (arrows) just inferior to angle of Gissane. These lesions appear to represent intraosseous ganglion cysts or remnant vessels penetrating the superior calcaneal cortex $[41,42]$
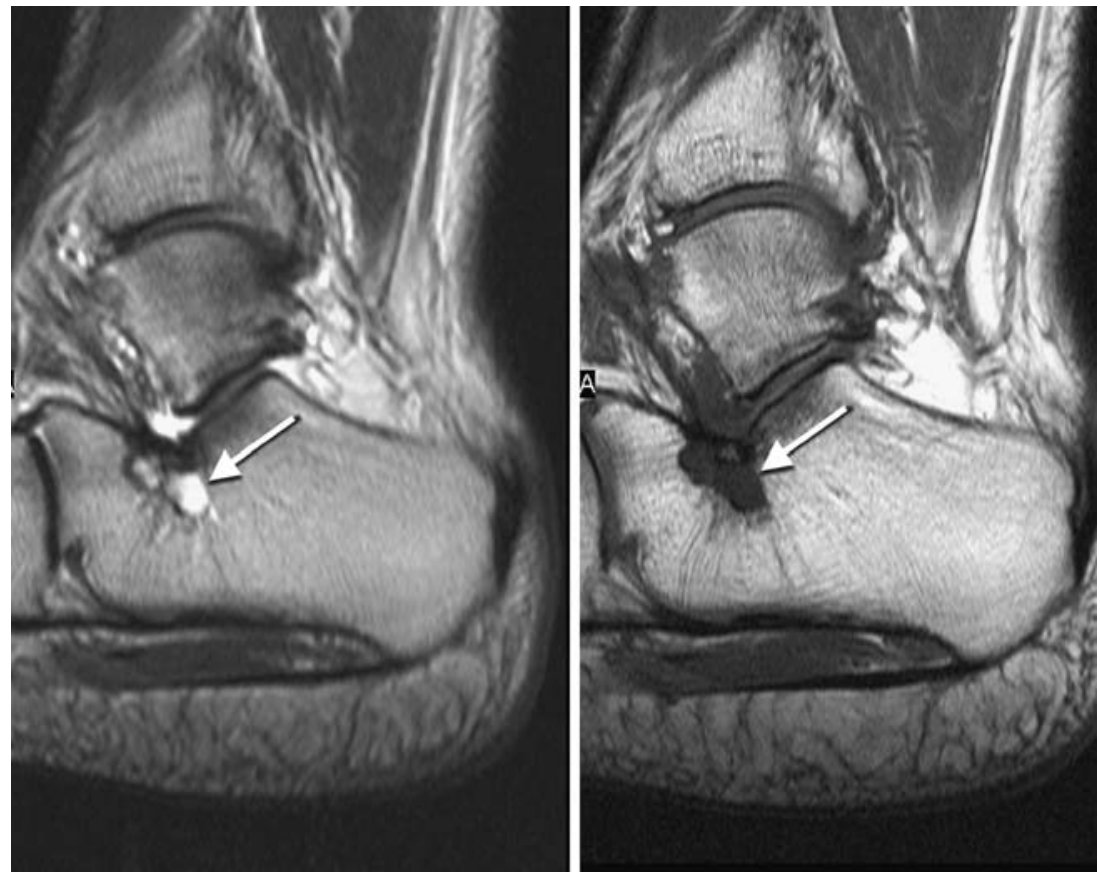
changes after immobilization do not have clinical features for reflex sympathetic dystrophy [40].

Bone marrow changes just inferior to angle of Gissane are commonly seen in asymptomatic volunteers [37]. These lesions represent intraosseous ganglion cysts or remnant vessels penetrating the superior calcaneal cortex [41, 42]. There is no correlation between patient age and lesion size and the presence of these foci [41] (Fig. 11).

Finally, a technical pitfall may occur when increased signals are falsely diagnosed as edema-like bone marrow abnormalities on MR sequences with inhomogeneous fat suppression on T2-weighted images. The STIR sequence is less sensitive to inhomogeneity of fat suppression than the T2-weighted fat-suppressed sequence [43].

\section{Conclusion}

When radiologists have to decide between clinically normal and early pathological findings in foot or ankle MR imaging, special attention has to be drawn to the complex anatomy of the foot and ankle (e.g., the deltoid ligament and the PTT insertion), the technical pitfalls (e.g., magic angle artifact, inhomogeneous fat suppression), and the high prevalence of asymptomatic findings (e.g., tiny bone marrow spots, cysts just inferior to the angle of Gissane). This knowledge should prevent inaccurate interpretations and overtreating of foot and ankle abnormalities.

\section{References}

1. Freyschmidt J, Brossmann J, Wiens J, Sternberg A. Freyschmidt's "Koehler/Zimmer" borderlands of normal and early pathological findings in skeletal radiography. New York, NY: Thieme; 2003.

2. Ogilvie-Harris DJ, Gilbart MK, Chorney K. Chronic pain following ankle sprains in athletes: the role of arthroscopic surgery. Arthroscopy 1997; 13: 564-574.

3. Sarrafian S. Anatomy of the foot and ankle: descriptive, topographic, functional. Philadelphia, PA: Lippincott; 1983.

4. Schneck CD, Mesgarzadeh M, Bonakdarpour A. MR imaging of the most commonly injured ankle ligaments. Part II. Ligament injuries. Radiology. 1992; 184: 507-512.

5. Verhaven EF, Shahabpour M, Handelberg FW, Vaes PH, Opdecam PJ. The accuracy of three-dimensional magnetic resonance imaging in the diagnosis of ruptures of the lateral ligaments of the ankle. Am J Sports Med 1991; 19: 583-587.

6. Duc SR, Mengiardi B, Pfirrmann CW, Hodler J, Zanetti M. Improved visualization of collateral ligaments of the ankle: multiplanar reconstructions based on standard 2D turbo spin-echo MR images. Eur Radiol 2007; 17: 1162-1171.

7. Kim S, Huh YM, Song HT, et al. Chronic tibiofibular syndesmosis injury of ankle: evaluation with contrast-enhanced fat-suppressed 3D fast spoiled gradient-recalled acquisition in the steady state MR imaging. Radiology 2007; 242: 225-235.
8. Vogl TJ, Hochmuth K, Diebold T, et al. Magnetic resonance imaging in the diagnosis of acute injured distal tibiofibular syndesmosis. Invest Radiol 1997; 32: 401-409.

9. Brown KW, Morrison WB, Schweitzer ME, Parellada JA, Nothnagel H. MRI findings associated with distal tibiofibular syndesmosis injury. Am J Roentgenol 2004; 182: 131-136.

10. Hintermann B, Knupp M, Pagenstert GI. Deltoid ligament injuries: diagnosis and management. Foot Ankle Clin 2006; 11: 625-637.

11. Koulouris G, Connell D, Schneider T, Edwards W. Posterior tibiotalar ligament injury resulting in posteromedial impingement. Foot Ankle Int 2003; 24: 575-583.

12. Mengiardi B, Pfirrmann CW, Vienne P, Hodler J, Zanetti M. Medial collateral ligament complex of the ankle: MR appearance in asymptomatic subjects. Radiology 2007; 242: 817-824.

13. Boss AP, Hintermann B. Anatomical study of the medial ankle ligament complex. Foot Ankle Int 2002; 23: 547-553.

14. Milner CE, Soames RW. The medial collateral ligaments of the human ankle joint: anatomical variations. Foot Ankle Int 1998; 19: 289-292.

15. Schneck CD, Mesgarzadeh M, Bonakdarpour A, Ross GJ. MR imaging of the most commonly injured ankle ligaments. Part I. Normal anatomy. Radiology 1992; 184: 499-506.

16. Delfaut EM, Demondion X, Bieganski A, Cotten H, Mestdagh H, Cotten A. The fibrocartilaginous sesamoid: a cause of size and signal variation in the normal distal posterior tibial tendon. Eur Radiol 2003; 13: 2642-2649.

17. Mengiardi B, Pfirrmann CW, Schottle PB, et al. Magic angle effect in MR imaging of ankle tendons: influence of foot positioning on prevalence and site in asymptomatic subjects and cadaveric tendons. Eur Radiol 2006; 16: 2197-2206.

18. Schweitzer ME, van Leersum M, Ehrlich SS, Wapner K. Fluid in normal and abnormal ankle joints: amount and distribution as seen on MR images. Am J Roentgenol 1994; 162: 111-114.

19. Mengiardi B, Pfirmann CW, Vienne P, et al. Anterior tibial tendon abnormalities: MR imaging findings. Radiology 2005; 235: 977-984.

20. Khoury NJ, el-Khoury GY, Saltzman CL, Brandser EA. Rupture of the anterior tibial tendon: diagnosis by MR imaging. Am J Roentgenol 1996; 167: 351-354.

21. Sobel M, Geppert MJ, Olson EJ, Bohne WH, Arnoczky SP. The dynamics of peroneus brevis tendon splits: a proposed mechanism, technique of diagnosis, and classification of injury. Foot Ankle 1992; 13: 413-422.

22. Wang XT, Rosenberg ZS, Mechlin MB, Schweitzer ME. Normal variants and diseases of the peroneal tendons and superior peroneal retinaculum: MR imaging features. Radiographics 2005; 25: 587-602.

23. Saupe N, Mengiardi B, Pfirrmann CW, Vienne P, Seifert B, Zanetti M. Anatomic variants associated with peroneal tendon disorders: MR imaging findings in volunteers with asymptomatic ankles. Radiology 2007; 242: 509-517.

24. Zanetti M, De Simoni C, Wetz H, Zollinger H, Hodler J. Magnetic resonance imaging of injuries to the ankle joint: Can it predict clinical outcome? Skeletal Radiol 1997; 26: 82-88.

25. Erdem CZ, Sarikaya S, Erdem LO, Ozdolap S, Gundogdu S. MR imaging features of foot involvement in ankylosing spondylitis. Eur J Radiol 2005; 53: 110-119.

26. Gigena LM, Chung CB, Lektrakul N, Pfirrmann CW, Sung MS, Resnick D. Transient bone marrow edema of the talus: MR imaging findings in five patients. Skelet Radiol 2002; 31: 202-207.

27. Ledermann HP, Morrison WB, Schweitzer ME. MR image analysis of pedal osteomyelitis: distribution, patterns of spread, and frequency of associated ulceration and septic arthritis. Radiology 2002; 223: 747-755.

28. Newman JS, Newberg AH. Congenital tarsal coalition: multimodality evaluation with emphasis on $\mathrm{CT}$ and MR imaging. Radiographics 2000;20:321-32. quiz 526-327, 532. 
29. O'Donnell P, Saifuddin A. Cuboid oedema due to peroneus longus tendinopathy: a report of four cases. Skeletal Radiol 2005; 34: $381-388$.

30. Trappeniers L, De Maeseneer M, De Ridder F, et al. Can bone marrow edema be seen on STIR images of the ankle and foot after 1 week of running? Eur J Radiol 2003; 47: 25-28.

31. Weishaupt D, Schweitzer ME. MR imaging of the foot and ankle: patterns of bone marrow signal abnormalities. Eur Radiol 2002; 12: 416-426.

32. Weishaupt D, Schweitzer ME, Alam F, Karasick D, Wapner K. MR imaging of inflammatory joint diseases of the foot and ankle. Skelet Radiol 1999; 28: 663-669.

33. James SL, Hughes RJ, Ali KE, Saifuddin A. MRI of bone marrow oedema associated with focal bone lesions. Clin Radiol 2006; 61: 1003-1009.

34. Zanetti M, Steiner CL, Seifert B, Hodler J. Clinical outcome of edema-like bone marrow abnormalities of the foot. Radiology 2002; 222: 184-188.

35. Miller TT, Staron RB, Feldman F, Parisien M, Glucksman WJ, Gandolfo LH. The symptomatic accessory tarsal navicular bone: assessment with MR imaging. Radiology 1995; 195: 849-853.

36. Morrison WB, Carrino JA, Schweitzer ME, Sanders TG, Raiken DP, Johnson CE. Subtendinous bone marrow edema patterns on MR images of the ankle: association with symptoms and tendinopathy. Am J Roentgenol 2001; 176: 1149-1154.
37. Zubler V, Mengiardi B, Pfirrmann $\mathrm{CW}$, et al. Bone marrow changes on STIR MR images of asymptomatic feet and ankles. Eur Radiol 2007; 17: 3066-3072.

38. Pal CR, Tasker AD, Ostlere SJ, Watson MS. Heterogeneous signal in bone marrow on MRI of children's feet: a normal finding? Skelet Radiol 1999; 28: 274-278.

39. Shabshin N, Schweitzer ME, Morrison WB, Carrino JA, Keller MS, Grissom LE. High-signal T2 changes of the bone marrow of the foot and ankle in children: red marrow or traumatic changes? Pediatr Radiol 2006; 36: 670-676.

40. Elias I, Zoga AC, Schweitzer ME, Ballehr L, Morrison WB, Raikin $\mathrm{SM}$. A specific bone marrow edema around the foot and ankle following trauma and immobilization therapy: pattern description and potential clinical relevance. Foot Ankle Int 2007; 28: 463-471.

41. Elias I, Zoga AC, Raikin SM, Schweitzer ME, Morrison WB. Incidence and morphologic characteristics of benign calcaneal cystic lesions on MRI. Foot Ankle Int 2007; 28: 707-714.

42. Fleming JL 2nd, Dodd L, Helms CA. Prominent vascular remnants in the calcaneus simulating a lesion on MRI of the ankle: findings in 67 patients with cadaveric correlation. Am J Roentgenol 2005; 185: 1449-1452.

43. Hilfiker P, Zanetti M, Debatin JF, McKinnon G, Hodler J. Fast spin-echo inversion-recovery imaging versus fast $\mathrm{T} 2$-weighted spin-echo imaging in bone marrow abnormalities. Invest Radiol 1995; 30: 110-114. 